Document downloaded from:

http://hdl.handle.net/10251/80589

This paper must be cited as:

Navarro-Peris, E.; Corberán Salvador, JM.; Martínez Galván, IO.; Gonzálvez Maciá, J. (2012). Oil sump temperature in hermetic compressors for heat pump applications. International Journal of Refrigeration. 35(2):397-406. doi:10.1016/j.jirefrig.2011.10.006.

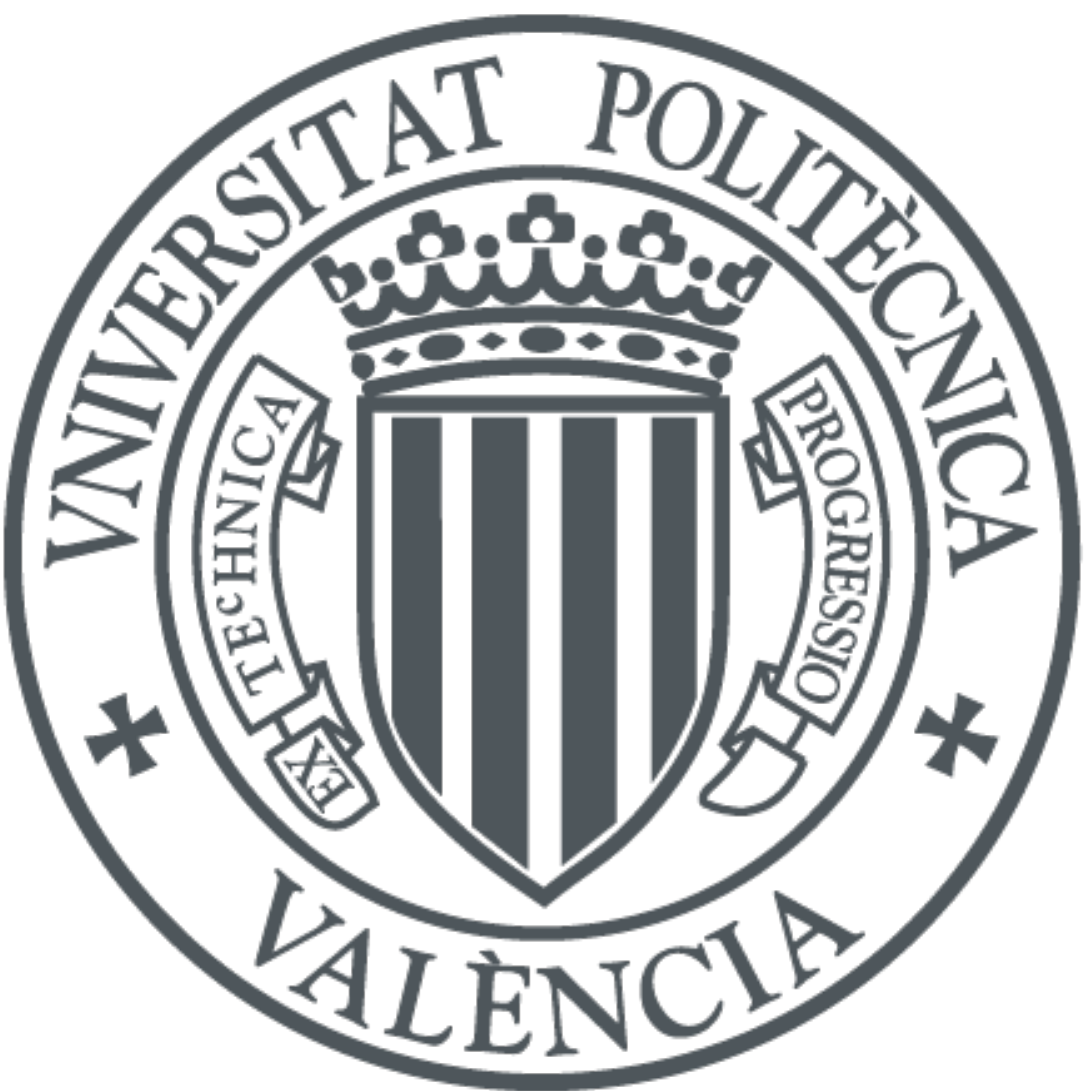

The final publication is available at

http://dx.doi.org/10.1016/j.jjefrig.2011.10.006

Copyright Elsevier

Additional Information 


\title{
Oil sump temperature in hermetic compressors for heat pump applications
}

\author{
Version $2.0^{*}$, \\ Universidad Politécnica de Valencia, Instituto de Ingeniería Energética, Investigación y \\ Modelado de Sistemas Térmicos, Camino de Vera, 14, 46022, Valencia, Spain.
}

\begin{abstract}
The oil temperature in the compressor sump is a critical factor describing the performance of a refrigeration system. It is the most important variable in order to describe the thermophysical properties of the lubricant fluid. However, it is not normally measured and it is not possible to determine the properties of oil-refrigerant mixture (inlet pressure and oil temperature are required).

In this paper, a set of test measuring the oil sump temperature for hermetic reciprocating and scroll compressors in a wide range of working conditions is presented. From these results and after a theoretical analysis of the factors with influence on this parameter, a correlation for the oil temperature as a function of compressor inlet and outlet conditions is presented, this correlation allows for the first time to estimate the oil sump temperature for scroll and hermetic reciprocating compressors from catalogue data with an error lower than $4 \mathrm{~K}$ degree for most of the cases.
\end{abstract}

Key words: Lubricant, Temperature, Performance, Refrigerants, Reciprocating compressor, Oil.

\footnotetext{
* corresponding author.Tel:(+34)-96-387-98-95, Fax:(+34)-96-387-95-29

Email address: enavarrodfis . upv. es (Version 2.0 ).
} 


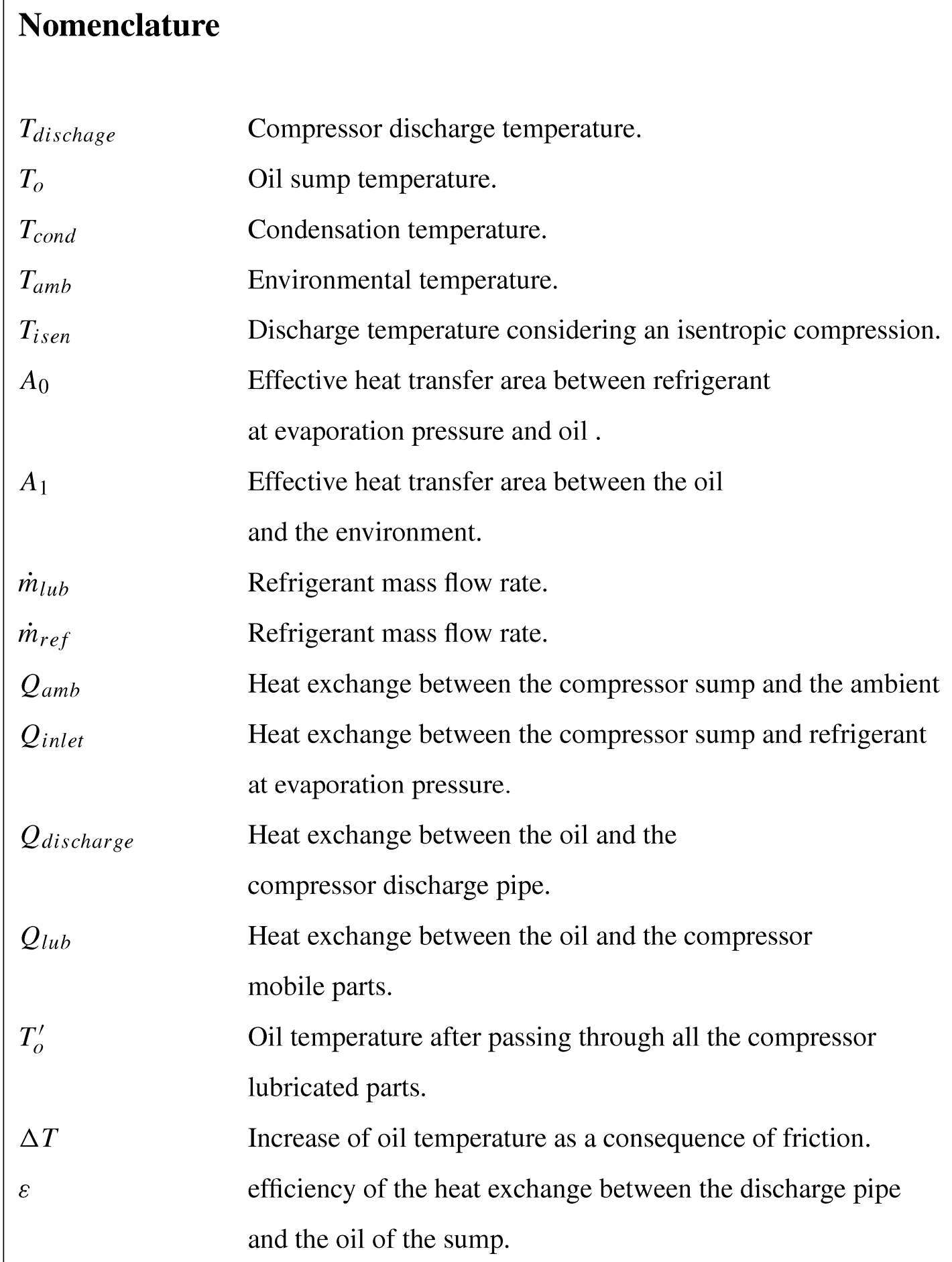




\section{Introduction}

Refrigeration industry as many other sectors is facing several challenges due to the increasing interest in environmental issues supported by the most representative national and international institutions. On the one hand, it is the problem of the direct emissions of refrigerants with a high global warming effect [1]. But on the other hand, the indirect emissions related to energy consumption of the refrigeration plants represents $80 \%$ of the global warming effect produced by this kind of systems [2],[3]. Refrigeration systems consume about $15 \%$ of all the electricity produced worldwide. Reducing the energy consumption of refrigeration systems has become now a key environmental priority $\lceil 2\rceil,\lceil 4\rceil$.

A fairly recent report issued by the Technical Options Committee of the United Nations Environmental Program (UNEP) on Refrigeration, Air Conditioning and Heat-Pumps, [2] indicates five technological areas where improvements for energy efficiency enhancement are possible, namely: 1) forced convection for evaporators and condensers, 2) lower viscosity oils, 3)reduction of the temperature level inside compressor, 4) variable speed motors, 5) insulation. 2), 3), 5) include the role of oil inside the compressor.

The main function of oil consists of the lubrication of the mechanical moving elements (pistons, connecting rod/crank, valves, ...) protecting them against wear with desirable minimum power losses. In this sense, the ability of oil to provide a proper lubrication is crucial for the energy efficiency, reliability and durability of these systems. However, the lubricant performs other important task inside the compressor like cooling the parts with higher motion, sealing the valves and the piston rings, protecting against corrosion or reducing the noise level [5].

The performance of the lubricant depends critically on the viscosity. A high viscosity reduce the efficiency and the compressor can lack the necessary flow requirements for an effective lubrication and wear can occur due to lubricant starvation in the bearing system. On the other side, a very low viscosity of the lubricant gives rise to direct metallic contact between the sliding parts of the system and poor sealing of the compression chamber.

In addition to pure oil viscosity, in refrigeration and air conditioning systems refrigerant is dissolved in the oil. This is a very suitable property which allows the return to the compressor along the refrigerant circuit of the oil expelled by it. However, the refrigerant solved in the oil sump changes the thermophysical properties of the lubricant fluid and constitutes a very important factor in the mechanical efficiency, valve sealing, wear or 
even in order to estimate the total refrigerant charge of the system. In fact, compressor can be the second element of a refrigeration system with most refrigerant charge in small capacity heat pumps as a consequence of the refrigerant solved in oil [8].

In that sense, temperature is one of the most influent parameters in the determination of lubricant mixtures properties as both viscosity and solubility depend strongly on it. However, up to the knowledge of the authors, most of the work related to oil temperature has been theoretical [10] or for a limited number of working conditions [11] and there is not much experimental information about the temperature of oil in the compressor and its dependency on the working conditions.

In this paper, we present the measured values of the oil sump temperature for a series of 4 hermetic piston compressors and one scroll compressor working in a wide range of operating conditions. A global analysis about which factors can have an influence in that temperature has been developed. From that study, the most influent variables in oil sump temperature has been found and an empirical correlation depending on this variables for the studied compressors has been proposed. The correlation allows the prediction of oil sump temperature as a function of the inlet and outlet conditions with an mean error lower than $4 \mathrm{~K}$ degrees.

\section{Experimental set up}

The hermetic piston compressor tests were performed in the test rig shown in fig.1. The test rig is provided with several PID control loops (compressor inlet and outlet pressure, superheat and subcooling controls) which allow an adjustment of the refrigerant conditions at compressor inlet (evaporating temperature and superheat) and outlet (condensing temperature) with a precision of $1 \mathrm{kPa}$. The rig is fully automated, and designed to permit working in steady state conditions for long time periods.

Other important characteristics of the test rig are that the mass flow rate is directly measured by means of a Coriolis-type (Fisher-Rosemount Micro-Motion CMF025M) and with the secondary refrigerant calorimeter based results. The accuracies of pressure transmitter (Fisher-Rosemount 3051) and temperature transmitter (RTD-PT 100) are $0.02 \%$ and $0.05^{\circ} \mathrm{C}$, respectively.

Two thermocouples type $\mathrm{T}$ were installed at the bottom of the compressor shell, and fixed to it with a thermally conductive epoxy. These thermocouples were isolated from the environment covering them with a flexible foam insulation piece. Considering the thermal conductivity of the cranckcase and the isolation from the environment of the 
thermocouple, it is assumed that the oil sump temperature in steady state is approximately the temperature registered by the thermocouples.

In this experimental set up, the oil sump temperature measurements were registered when the compressor was operating in steady state in the following conditions:

(1) For a serie of four hermetic piston compressors in working conditions going from $-20^{\circ} \mathrm{C}$ to 15 of evaporation temperature and from 35 to 65 of condensation temperature for a constant superheat of $11.1 \mathrm{~K}$ (fig. 2 summarizes all the test). The compressors have nominal capacities from $1.5 \mathrm{~kW}$ to $15 \mathrm{~kW}$ and their main characteristics are described in table 1 . In these compressors the stroke and the cylinder number are changed in order to study the dependence of oil temperature on the compressor size. Compressors with the same number of pistons have the same crankcase size

(2) For the compressor SO, a serie of additional tests in which superheat varies between 10 and $30 \mathrm{~K}$ maintaining the compressor evaporation and condensation temperatures in the same range of the previous test.

(3) Repeating the experiments described on the second point but using $\mathrm{R} 407 \mathrm{C}$ as refrigerant.

The selected Scroll compressor has a nominal capacity similar to the ST reciprocating compressor. Its tests have been performed in a test bench facility designed for the characterization of water to water heat pumps fig 3. This rig allows establishing different operating condition under both heating and cooling modes. It basically consists of two hydraulic groups that simulate the cooling/heating load conditions at the indoor-side and outdoor-side water circuits. The test facility includes measurement of inner and outer water temperatures in both loops, and the corresponding water mass flow rates. The compressor electrical input is measured with an error of $0.1 \%$. The refrigerant pressure is measured with an absolute pressure transducers with an accuracy of $0.03 \%$, while T-type thermocouples able to measure the temperature with a precision of $\pm 0.5 \mathrm{~K}$ are employed to estimate the refrigeration cycle operation parameters. The mass flow rate of the refrigerant is not directly measured but estimated from the heat balance in the evaporator and condenser. A cross comparison between the estimated values at both heat exchangers allows to check the accuracy of the measurement. The difference between both measurements lies in a band of $\pm 3 \%$, which can be stated as the uncertainty band for the refrigerant mass flow rate.

In this test bench compressor oil sump temperature were registered in 220 test performed in a wide range of condensation temperatures $\left(30^{\circ} \mathrm{C}-70^{\circ} \mathrm{C}\right)$ at evaporation temperatures between 0 and 5 degrees when the rig was operating in steady state. The selection of different operating conditions was a result of the fact that this compressor was employed 
in a prototype mainly targeted to cooling applications in Mediterranean climates.

\section{Results and discussion}

\subsection{Obtained results}

Figure 4 represents the measured oil temperature as a function of test conditions (evaporation and condensation temperatures) for a constant superheat in the tested reciprocating compressors. The figure shows that oil temperature increases with condensation temperature and considering a constant condensation temperature, it increases as evaporation temperature decreases. Comparing the mean temperature data for the different compressors (table 2), compressors with the same number of pistons increases the oil sump temperature with the size (between $6 \mathrm{~K}-8 \mathrm{~K}$ degrees) and comparing compressors with the same stroke, oil sump temperature increases with the number of pistons (between 2 $\mathrm{K}-3 \mathrm{~K}$ degrees for an increment of approximately $25 \%$ ).

Figure 5 shows the results obtained for the compressor SO operating with a superheat between 10 and 30 degrees with propane and with R407C. The figure appears more irregular pointing to a lower correlation of oil sump temperature with evaporation and condensation temperature when superheat is changed. Comparing both refrigerants, $\mathrm{R} 407 \mathrm{C}$ has a $10 \mathrm{~K}$ degrees higher temperature than propane on average.

Figure 6 plots the oil sump temperature as a function of evaporation and condensation temperature for the scroll compressor using propane as refrigerant. The temperature trend on this compressor is qualitatively similar to the observed in reciprocating compressors but oil temperature is significantly lower (between $10 \mathrm{~K}-15 \mathrm{~K}$ degrees on average). Probably, this will be due to the fact that scroll compressor usually isolates more efficiently the compressor inlet and discharge parts, which results in a higher temperature gradient between both sides than piston compressors in the crankcase.

\subsection{Analysis of the different factors influencing oil sump temperature}

The oil sump temperature in steady state is an equilibrium between the different heat sources represented in figs. 7 and 8 . Therefore, it can be derived from the following balance: 


$$
Q_{\text {lub }}+Q_{\text {discharge }}=Q_{\text {inlet }}+Q_{a m b}
$$

where $Q_{l u b}$ is the heat transferred by the oil coming back to the sump after passing through all the mechanical parts of the compressor. This heat can be estimated by the following expression

$$
Q_{l u b}=\dot{m}_{l u b}\left(T_{o}^{\prime}-T_{o}\right)
$$

where $\dot{m}_{l u b}$ is the mass flow rate of the oil absorbed from the sump to the mobile parts of the compressor. This oil will have to way to come back to the sump:

- Once the oil has passed through the internal compressor parts like crankshaft, the mobile parts of the compressor chamber or the compressor wall, it returns to the sump.

- A part of the previous initial oil flow arrives to the compression chamber where is pumped out the compressor instead of being recirculated. It returns to the compressor sump through the suction at the inlet temperature.

$T_{o}^{\prime}$ is the oil temperature after passing the lubricated compressor parts and $T_{O}$ the oil sump temperature. $T_{o}^{\prime}$ depends mainly on two factors:

$$
T_{o}^{\prime}=\left\{\begin{array}{cc}
\Delta T \sim & \text { lubricantviscosity } \\
& T_{\text {inlet }}+T_{\text {discharge }}(\text { piston }) \\
T \sim & T_{\text {discharge }}(\text { scroll })
\end{array}\right.
$$

The first one is the viscosity because when it increases there is more friction between the lubricant and compressor moving parts and the lubricant increases more its temperature, the second one is on the operating conditions.

$Q_{\text {discharge }}$ represents the heat supplied by the discharge pipe in compressor where this pipe passes through the sump before going out the compressor (see fig. 7). This heat can be described in a simple way by the following expression:

$$
Q_{\text {discharge }}=\varepsilon \dot{m}_{\text {ref }} c_{p g}\left(T_{\text {discharge }}-T_{o}\right)
$$

with $\varepsilon$ the heat exchange efficiency between the discharge pipe and the oil, $\dot{m}_{r e f}$ the mass 
flow rate of the refrigerant, $c_{p g}$ the specific heat capacity at constant pressure for the refrigerant, and $T_{\text {discharge }}$ the compressor discharge temperature.

$Q_{\text {inlet }}$ is the heat transferred between the oil and the refrigerant of the crankcase and is approximated by:

$$
Q_{\text {inlet }}=A_{0} h_{\text {inlet }}\left(T_{o}-T_{\text {inlet }}\right)
$$

where $A_{0}$ is the oil sump surface in contact with the inlet refrigerant and $h_{\text {inlet }}$ is the heat transfer coefficient between the oil and the refrigerant.

$Q_{a m b}$ is the heat exchange between the sump and the environment and given by:

$$
Q_{a m b}=A_{1} U\left(T_{o}-T_{a m b}\right)
$$

$A_{1}$ in the compressor crankcase area in contact with the oil sump (this area will depend on the oil temperature, refrigerant-oil solubility and the evaporation pressure) and $U$ is the global heat transfer coefficient with the ambient.

Thus, the heat balance can be expressed as a function of the inlet and outlet conditions in the following way:

$$
\begin{aligned}
\dot{m}_{\text {lub }}\left(T_{o}^{\prime}-T_{o}\right)+\delta \varepsilon \dot{m}_{r e f} c_{p g}( & \left.T_{\text {discharge }}-T_{o}\right)= \\
& A_{0} h_{\text {inlet }}\left(T_{o}-T_{\text {inlet }}\right)+A_{1} U\left(T_{o}-T_{a m b}\right)
\end{aligned}
$$

where $\delta$ will be 1 if the compressor discharge pipe passes through the oil before going out the compressor and 0 otherwise. Expressing $T_{o}^{\prime}$ in terms of the inlet and outlet conditions, the final equation is :

$$
\begin{array}{r}
\dot{m}_{\text {lub }}\left[\varphi\left(T_{o}+\Delta T\right)+(1-\varphi)\left(\alpha T_{\text {inlet }}+(1-\alpha) T_{\text {discharge }}\right)+\delta \varepsilon \dot{m}_{r e f} c_{p g}\left(T_{\text {discharge }}-T_{o}\right)=\right. \\
A_{0} h_{\text {inlet }}\left(T_{o}-T_{\text {inlet }}\right)+A_{1} U\left(T_{o}-T_{\text {amb }}\right)
\end{array}
$$

being $\varphi$ and $\alpha$ two weight coefficients. $\varphi$ gives the relative importance of the friction heating of the refrigerant and $\alpha$ gives the relative importance that inlet and discharge temperature have in the increase $T_{o}^{\prime}$. For instance, it is expected that the lubricated mobile parts (cylinder and crankshaft) are closer to the evaporation temperature in piston compressor while in scroll compressor the lubrication of the mobile pieces are closer to 
the discharge part, hence $\alpha$ should be higher for a piston compressor than for a scroll compressor.

From all the previous development, the oil sump temperature $T_{o}$ is given by:

$$
\begin{aligned}
T_{o}=\frac{\dot{m}_{l u b} \varphi}{C_{o i l}} \Delta T+\frac{A_{1} U}{C_{o i l}} T_{a m b}+ \\
\quad \frac{(1-\varphi) \alpha+A_{0} h_{\text {inlet }}}{C_{\text {oil }}} T_{\text {inlet }}+\frac{(1-\alpha)(1-\varphi)+\delta \varepsilon \dot{m}_{\text {ref }} c_{p}}{C_{\text {oil }}} T_{\text {discharge }}
\end{aligned}
$$

with $C_{o i l}=A_{0} h_{\text {inlet }}+A_{1} U+\delta \varepsilon \dot{m}_{r e f} c_{p}-\dot{m}_{l u b} \varphi$

According to that expression, the oil sump temperature will depend on compressor inlet and discharge temperatures, on the refrigerant mass flow rate, on the evaporation pressure through $A_{1}$, on the ambient temperature and on other variables more difficult to quantify like lubricant flow $\dot{m}_{l u b}$ (probably it is independent of the working conditions, at least for constant superheat), properties of the refrigerant-oil mixture (viscosity, density and the like) or the heat transfer area between the lubricant and the inlet refrigerant (the inlet refrigerant is constantly mixing with the oil of the sump and there is not a well defined surface between them). In addition, the relations between the variables are not linear which makes complicated the global evaluation of the parameters of the equation.

\subsection{Experimental Correlations}

The theoretical development of the previous section gives an approach of the variables having an influence in oil sump temperature. Nevertheless, considering the amount of parameters and the nonlinear cross dependencies, a simplification of eq.8 is required in order to have a more practical expression dependent on variables that can be measured easily.

With this objective, it was assumed that in eq.8 compressor inlet and discharge temperature will be the most influential factors in oil sump temperature and other parameters like $\Delta T$ will be independent of the working conditions. Hence, a linear correlation on both variables is assumed.

$$
T_{o}=C_{1} T_{\text {discharge }}+C_{2} T_{\text {inlet }}+C_{3}
$$


Under this approach, the experimental data of the four reciprocating compressors have been fitted to expression 9. The obtained values for the parameters are shown in table 3. Fig. 9 represents the comparison between the experimental and the correlated values. It shows that oil sump temperature is predicted by the assumed linear approach with an error lower than $4 \mathrm{~K}$ degrees for most of the cases and a mean error lower than $2 \mathrm{~K}$.

According to the values obtained for the $C_{i}$ parameters shown in table 3 and comparing them with eq. 8 , several relations can be deduced:

- All the parameters are positive.

- $C_{1}>C_{2}$ : Discharge temperature has more influence in the oil sump temperature than inlet temperature.

- Compressors with the same number of pistons have a similar value of $C_{2}$ (parameter associated with inlet temperature), these compressors have the same crankcase size and probably they have a similar value for $A_{0}$

- Compressors with the same stroke have a closer value of $C_{1}$ (parameter associated with discharge temperature). On the one side this fact can be related to similar oil friction areas per unit of oil flow for compressors with the same stroke ( $\Delta T$ is associated with lubricant viscosity), on the other side compressors with the same stroke have a similar ratio between mass flow and discharge pipe area.

In order to evaluate the application range of the obtained correlation, the additional measurements developed for SO compressor at different superheats and with both refrigerants were compared with the corresponding values obtained using the correlation. Results are shown on fig. 10.

R407C oil sump temperature is described with an error lower than $5 \mathrm{~K}$ degrees by the same correlation used for propane. However, a small shift in the slope of the deviation between the experimental and the correlated results is detected, this shift makes that the measured R407C temperatures are 2-3 K degrees higher for low oil temperatures $(45 \mathrm{~K}$ $55 \mathrm{~K}$ degrees) and the opposite for high oil temperatures (75 K - $85 \mathrm{~K}$ degrees). Probably this deviation is a consequence of the dependency of $T_{o}$ in eq. 8 on the refrigerant and the refrigerant-oil mixture. Nevertheless, considering that HC and HCF have quite different oil solubility properties and that a difference of 3 degrees does not change substantially the oil-refrigerant mixture properties, the influence of the oil-refrigerant mixture in the oil sump temperature can be neglected at least for a wide spectrum of refrigerants. From this analysis, it can also be established that the higher oil temperature observed with $\mathrm{R} 407 \mathrm{C}$ is mainly attributable to the higher compressor discharge temperature for this refrigerant.

Regarding scroll compressor, the same lineal approach has been taken and the obtained 
values for the $C_{i}$ parameters are shown on table 3 . In this case all the parameters are also positive. $C_{1}$ and $C_{2}$ are very close, hence inlet temperature is more important in the oil temperature in a scroll compressor than in a piston compressor. The value of $C_{3}$ is in the same range than the obtained for piston compressor.

The correlation coefficient is also higher than 0.95 . Thus, in this case the liniarized correlation seems to be a good approach too. Nevertheless, as it is over 0.9, the lineal approach can be considered reasonable for this case too as it can be seen in fig 11 where correlated values are represented compared with the measured values.

Although the obtained correlation describes properly the behavior of oil sump temperature, its main drawback is that compressor discharge temperature is usually not available. In order to solve this problem the authors have been tested other effective linear correlations (see fig 12 to check some of the test). From all this work, a linear dependence in compressor inlet temperature and isentropic discharge temperature shows the higher correlation index and lower mean square error if discharge temperature is not available.

$$
T_{o}=C_{1} T_{i s e n}+C_{2} T_{\text {inlet }}+C_{3}
$$

The results obtained for this approach are presented in table 4 . The correlation index has been reduced in all the cases. The mean error is lower than $4 \mathrm{~K}$ degrees. There is no theorical expression in order to analyze the obtained results using this correlation and so, the values of the parameters do not have a straightforward interpretation. Nevertheless some comments can be made about the obtained results. For all the compressors, the parameter $C_{1}$ increases compared with the corresponding paramenter of eq 9 . This is due to the fact that isentropic temperature is lower than discharge temperature. In response $C_{2}$ is reduced reaching even negative values for the piston compressors where $C_{2}$ value was lower than $C_{2}$ value for scroll compressor as shown in eq.9.

\section{Conclusions}

Compressor oil temperature is a parameter of major relevance in order to define the thermophysical properties like solubility and viscosity of the lubricant fluid. In this paper we report a serie of test which the oil sump temperature is measured in for two specific hermetic compressor designs (scroll and reciprocating) using propane as refrigerant.

The experimental measurements of oil sump temperature for 4 reciprocating compressors at several superheat with two refrigerants and a scroll compressor have been reported. 
From these measurements it has been established that R407C has a higher oil sump temperature than propane $(15 \mathrm{~K})$. Scroll compressor has lower oil sump temperature than piston compressor $(10 \mathrm{~K})$.

A theoretical analysis of the different variables which can have an influence on the oil sump temperature has been carried out. From the experimental data it has been established that the discharge temperature and inlet temperature are the most influent variables and the oil sump temperature has been correlated with these variables. The correlation has been able to predict the oil sump temperature with an error lower than $4 \mathrm{~K}$ degrees in almost all the conditions.

From the obtained correlations, it results that discharge temperature is the most influent factor in the oil sump temperature for hermetic piston compressor while both temperatures have the same weight in the final oil sump temperature for scroll compressor.

The dependency of the correlation on the used refrigerant has been weak enough to allow in a first approach the use of it independently of the refrigerant.

This study will allow the estimation of refrigerant oil mixture properties like viscosity and solubility, improving the estimation of the magnitudes like the total charge of the system which can be very useful to improve simulation softwares of the steady state performance and cost of a vapor compression system like [15], [16], [17].

Moreover, considering that heat is generated mainly in the compression process and in the friction between the sliding parts [6], its role in compressor cooling can be quite significant ([7] estimates between 5\%-10\% of the heat generated in the compressor can be absorbed by the oil). Thus, the supplied correlations can be used as a boundary conditions in compressor temperature models like [11],[12],[13].

\section{Acknowledgements}

This work has been partially funded by the Spanish Ministerio de Ciencia e Innovacion through project, ref. DPI 2008-06707-C02-01(Estudio de optimizaciï $; 1 / 2 n$ de equipos frigorificos de aire acondicionado para su funcionamiento con refrigerantes naturales (hidrocarburos)).

\section{References}

[1] Veldersa GJM, Faheyb DW, Danielb JS, McFarlandc $\mathrm{M}$, Andersend EO. The large contribution of projected HFC emissions to future climate 
forcing. Proceedings of the National Academy of Sciences of the United States of America. http://www.pnas.org/cgi/doi/10.1073/pnas.0902817106

[2] Coulomb D. Refrigeration:The challenges associated with sustainable development. Proceedings of the 6th International Conference on Compressors and Coolants 2006. Slovak Republic. CD-Rom.

[3] Trott AR, Welch T. Refrigeration and Air conditioning. Third Edition. ButterworthHeinemann 2000.

[4] Billiard F. Refrigerating equipment, energy efficiency and refrigerants. Proceedings of the 5th International Conference on compressors and coolants 2004. Slovak Republic. 36-43.

[5] Watson MC. Thermodynamics and heat transfer: Lubrication. Proceedings of the Centenary Conference of the Institute of Refrigeration, London, IMechE, UK, 1999.

[6] Prata AT, Barbosa JR. Role of the Thermodynamics, heat transfer and fluid mechanics of lubricant oil in hermetic reciprocating compressors. Heat Transfer Engineering 2009. 30(7); 533-548.

[7] Wang SK, Handbook of air conditioning and refrigeration, 2nd edition, McGraw-Hill, New York, 2000.

[8] Fernando P, Palm B, Lundqvist P, Granryd E, Propane heat pump with low refrigerant charge:design and laboratory test. International Journal of Refrigeration 2004. 27; 761.

[9] Youbi-Idrissi M, J Bonjour. The effect of oil in refrigeration: Current research issues and critical review of thermodynamic aspects. International Journal of Refrigeration 2008. 31 (2); 165-179.

[10] Hsieh JJ, Lee WS, Wu WF, Chen SL. Effect of lubrication on the performance and dynamic loads of scroll compressor. Chinese Journal of Mechanics. 2001. 17 201-210.

[11] Dutra T, Deschamps CJ. Experimental Investigation of Heat Transfer in Components of a Hermetic Reciprocating Compressor. 20th International conference of compressors at purdue. 2010. 1346.

[12] Almbauer RA, Burgstaller A, Abidin Z, Nagy D. 3-Dimensional Simulation for Obtaining the Heat Transfer Correlations of a Thermal Network Calculation for a Hermetic Reciprocating Compressor. Proceddings of the International Compressor Engineering Conference at Purdue, 2006. C079.

[13] Ooi KT. Heat Transfer Study of a Hermetic Refrigeration Compressor. Applied Thermal Engineering, 2003. 23; pp. 1931-1945.

[14] Ribas Jr., F. A., Deschamps, C. J., Fagotti, F., Morriesen, A., Dutra, T., 2008. Thermal Analysis of Reciprocating Compressors - A Critical Review. Proc. Int. Compressor Engineering Conf. Purdue, paper 1306. 
[15] Domanski PA, Didion DA, Chi J. 2003, NIST Vapor Compression Cycle Design Program CYCLE-D, Ver. 3.0. Standard Reference Database 49, National Institute of Standards and Technology; Gaithersburg, MD, USA.

[16] Richardson D, An object oriented simulation framework for steady-state analysis of vapor compression refrigeration systems and components, $\mathrm{PhD}$ thesis, Department of Mechanical Engineering, University of Maryland, College Park, 2006.

[17] Corberán JM, Gonzálvez J, Montes P, Blasco R. ART: a computer code to assist the design of refrigeration and a/c equipment, in: 8th International Refrigeration Conference, Purdue, 20() ). 


\section{Figure Index}

- Figure 1 Scheme of the used test rig to evaluate the oil sump temperature of reciprocating compressor.

- Figure 2 Test Matrix for the serie of reciprocating compressors.

- Figure 3 Scheme of the used test rig for scroll compressor.

- Figure 4 Oil sump temperature for the four reciprocating compressors.

- Figure 5 Oil sump temperature for the SO compressor working in a superheat range from $10 \mathrm{~K}$ to $30 \mathrm{~K}$ for propane and $\mathrm{R} 407 \mathrm{C}$.

- Figure 6 Oil sump temperature for the scroll compressor.

- Figure 7 Scheme of the oil heat transfer processes in the cranckcase of a hermetic reciprocating compressor.

- Figure 8 Scheme of the oil heat transfer processes in the cranckcase of a scroll compressor.

- Figure 9 Comparison of oil sump temperature from correlated and measured oil sump temperature for reciprocating compressors using linear correlation depending on the discharge and inlet temperature.

- Figure 10 Comparison of the measured oil sump temperature for the SO compressor using propane and R407C with several superheats and the calculated value using the correlation obtained for this compressor working with R290 at constant superheat.

- Figure 11 Comparison of oil sump temperature from correlated and measured oil sump temperature for scroll compressors using linear correlation depending on the discharge and inlet temperature.

- Figure 12 Oil sump temperature as a function of compressor variables commonly supplied by manufacturers. 


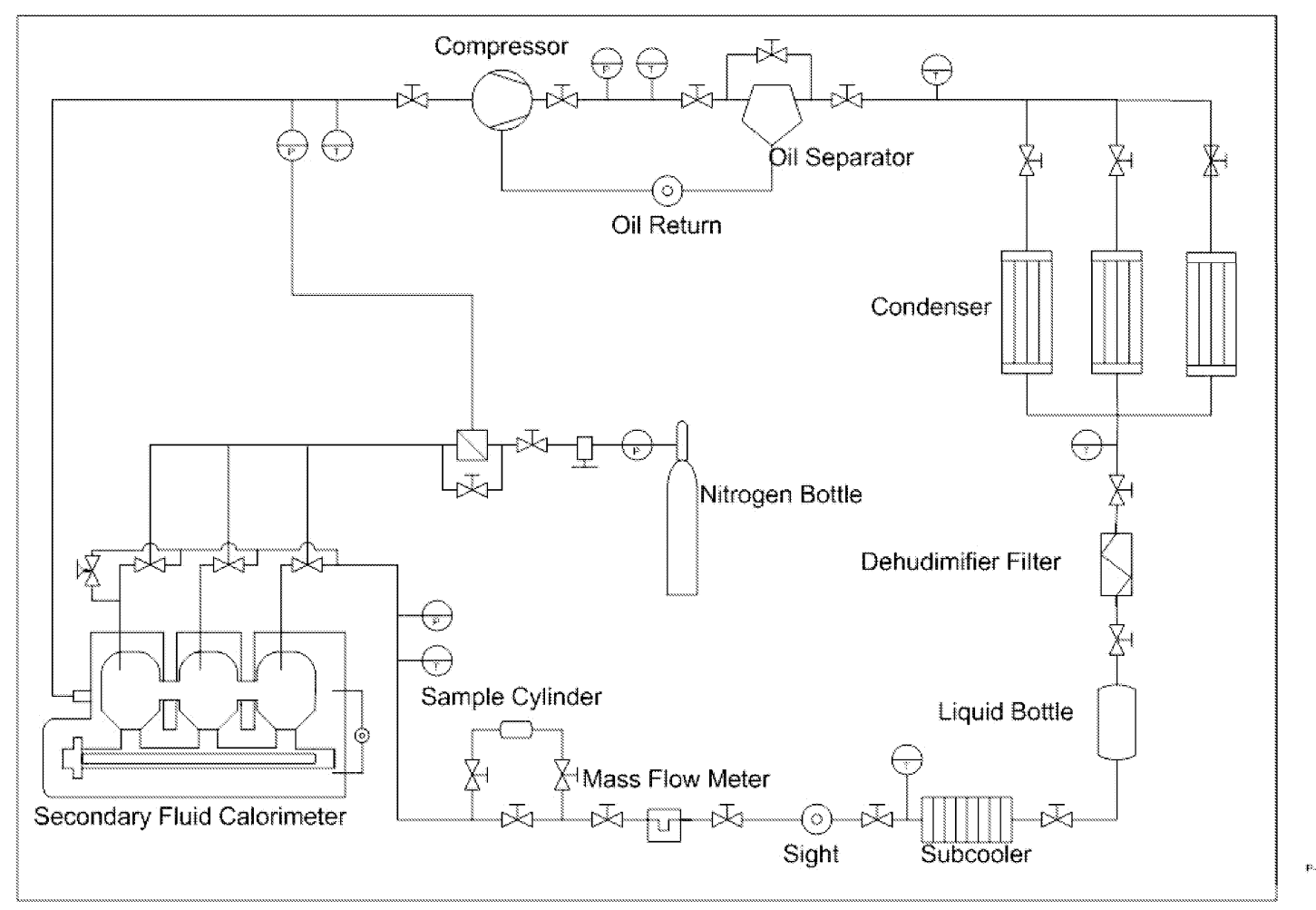

Figure 1. 


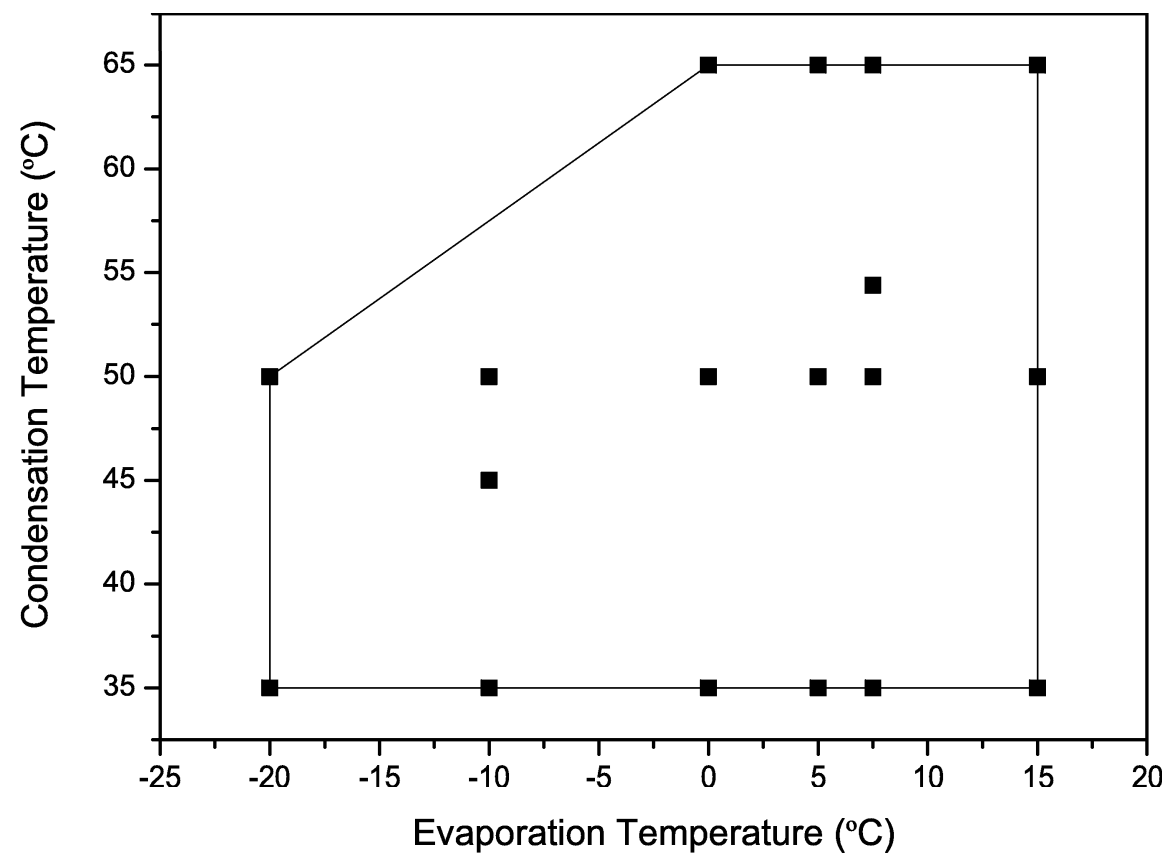

Figure 2. 


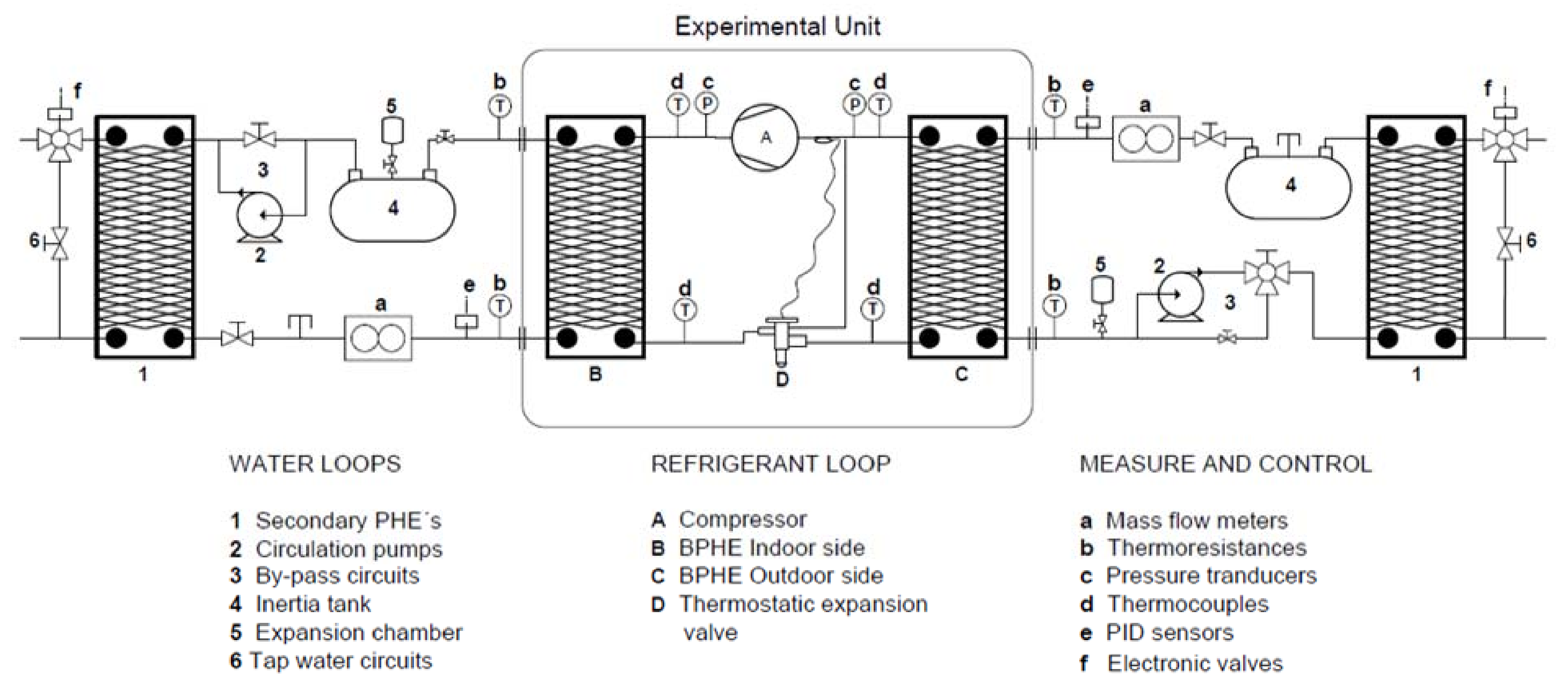



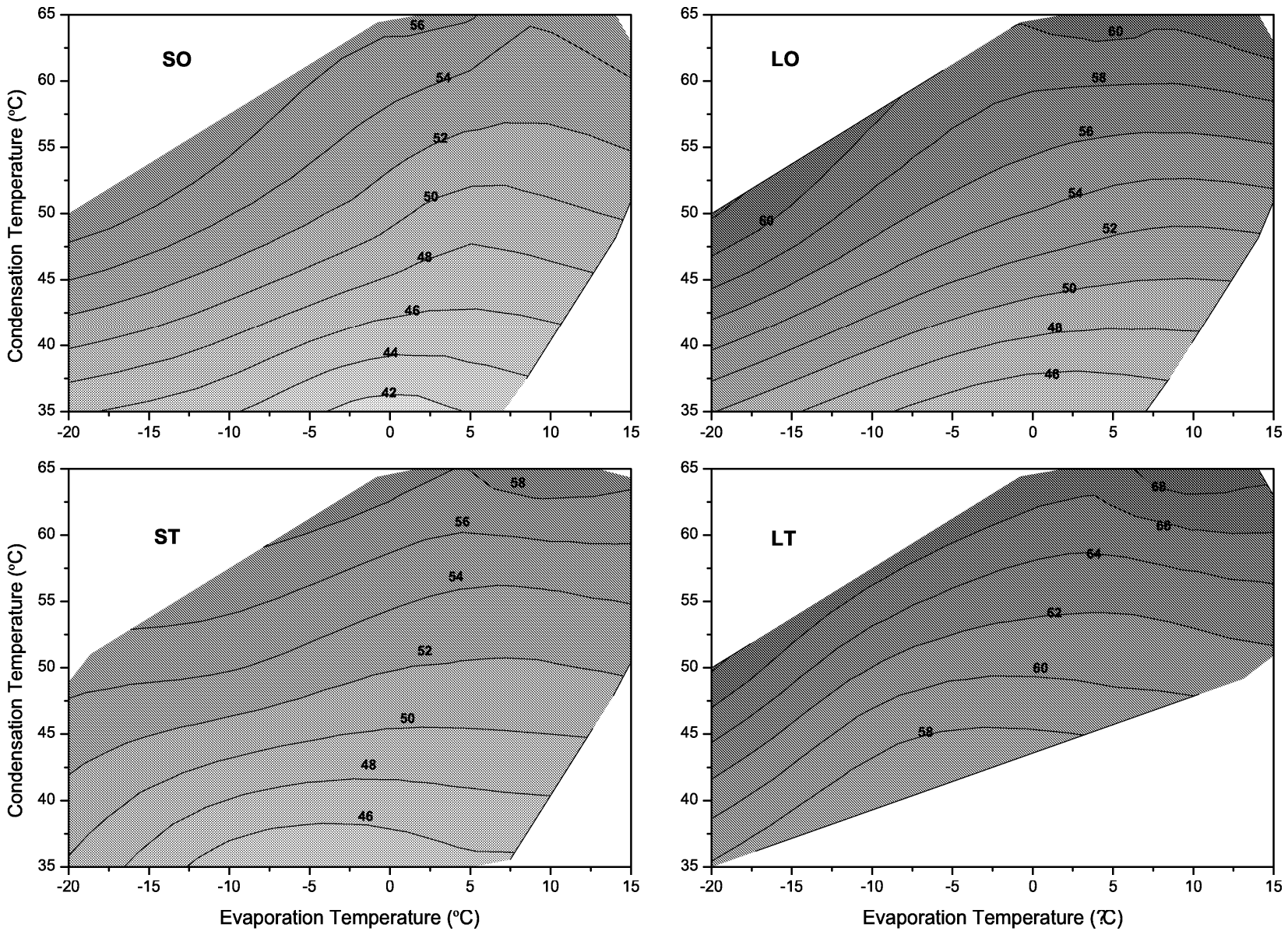

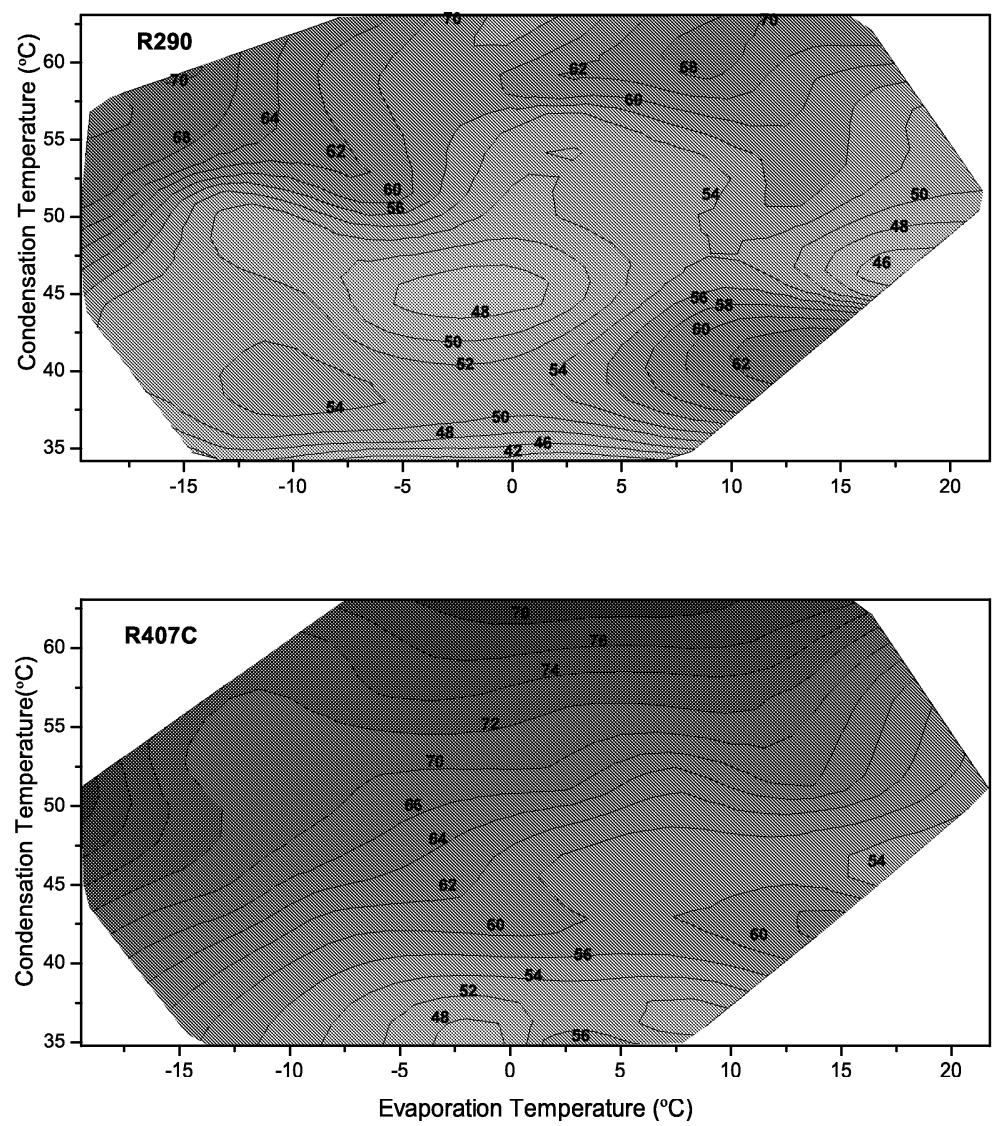


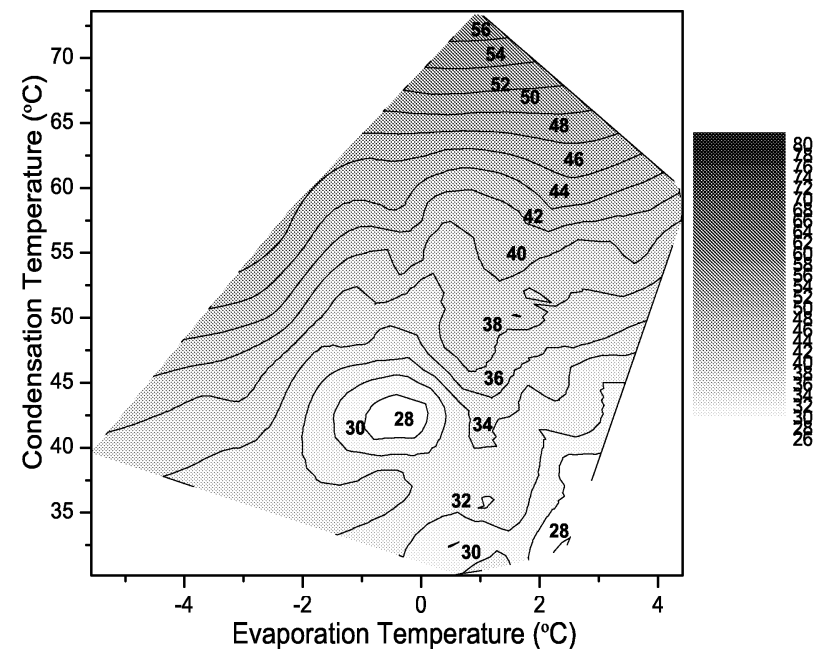

Figure 6. 


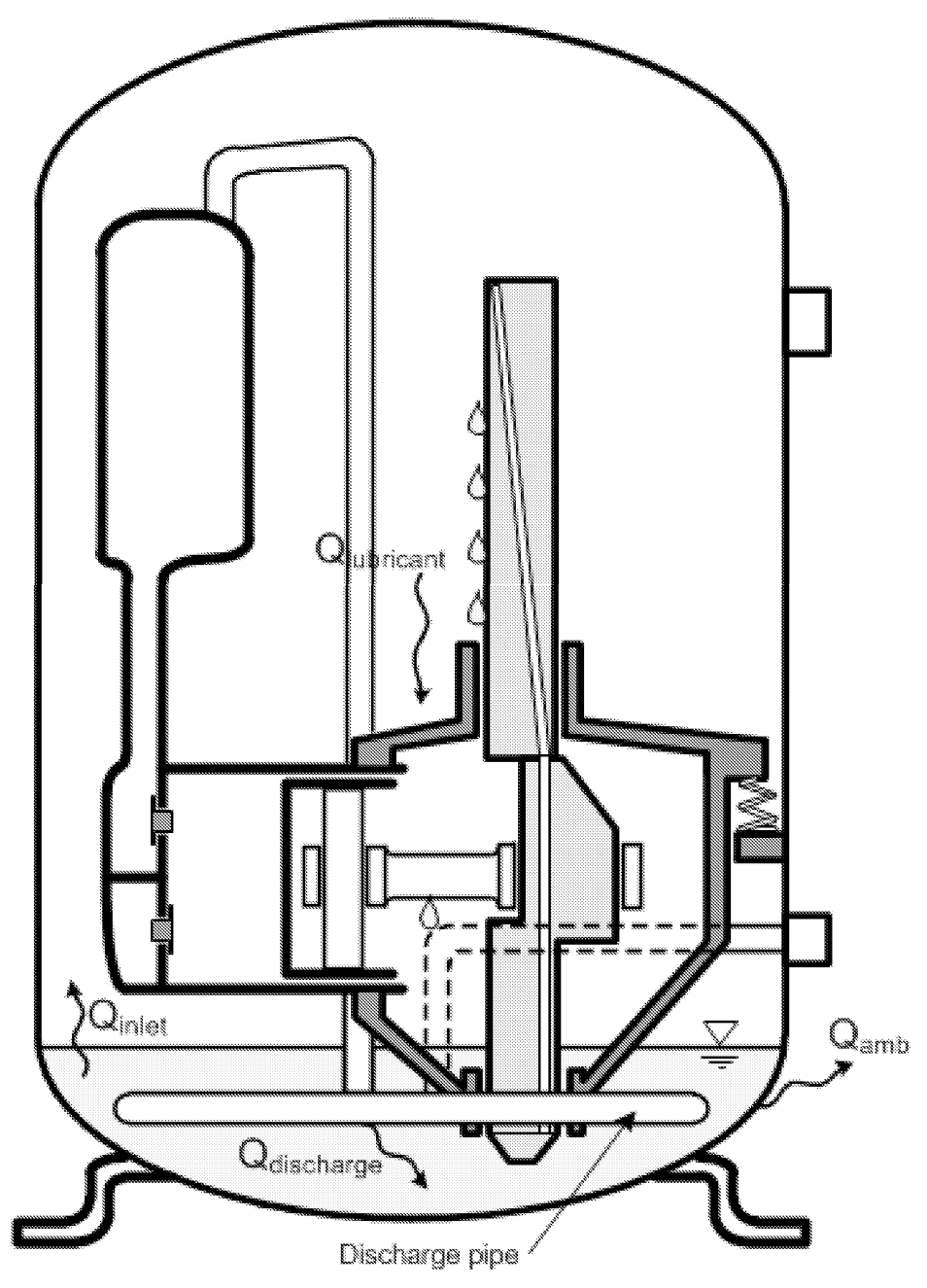




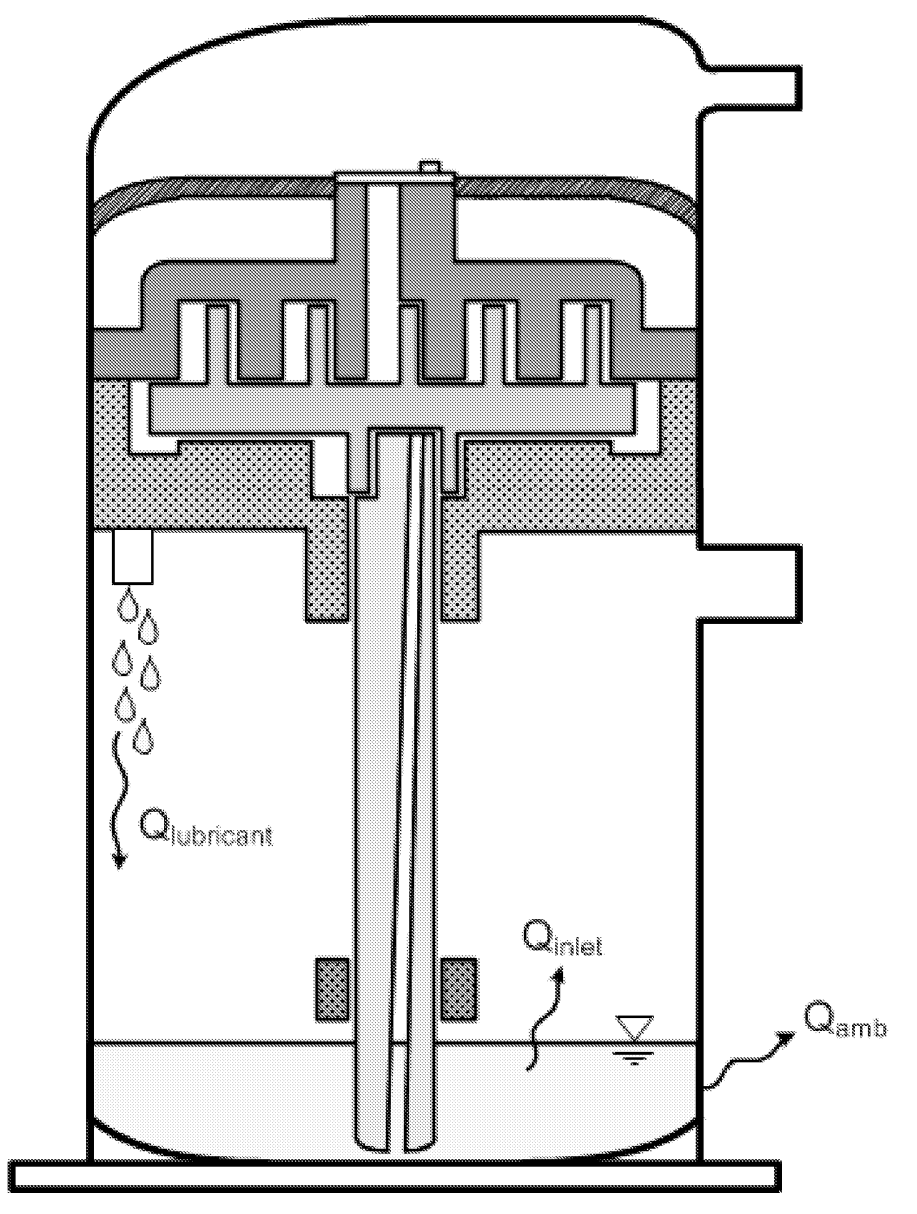




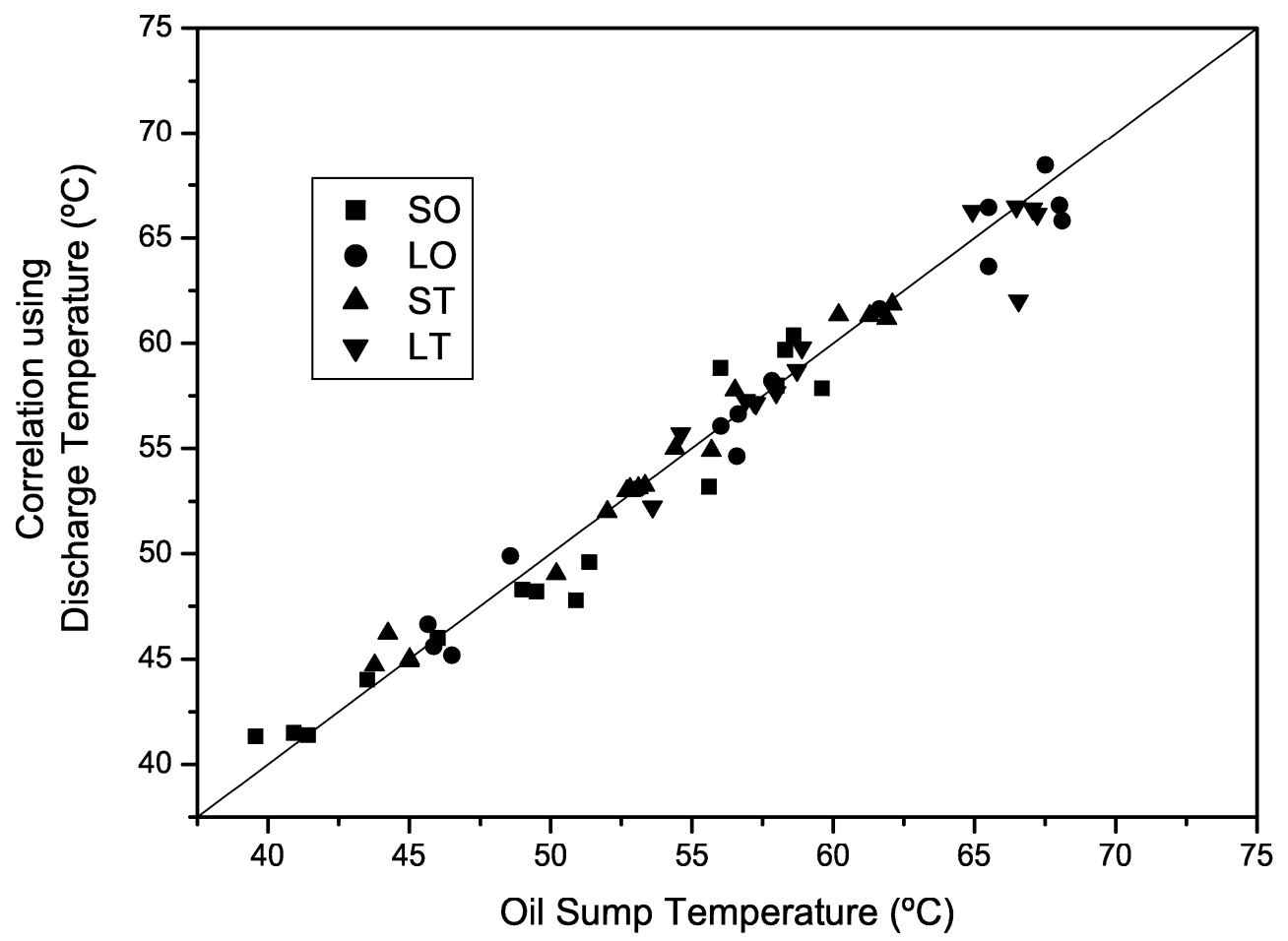

Figure 9. 


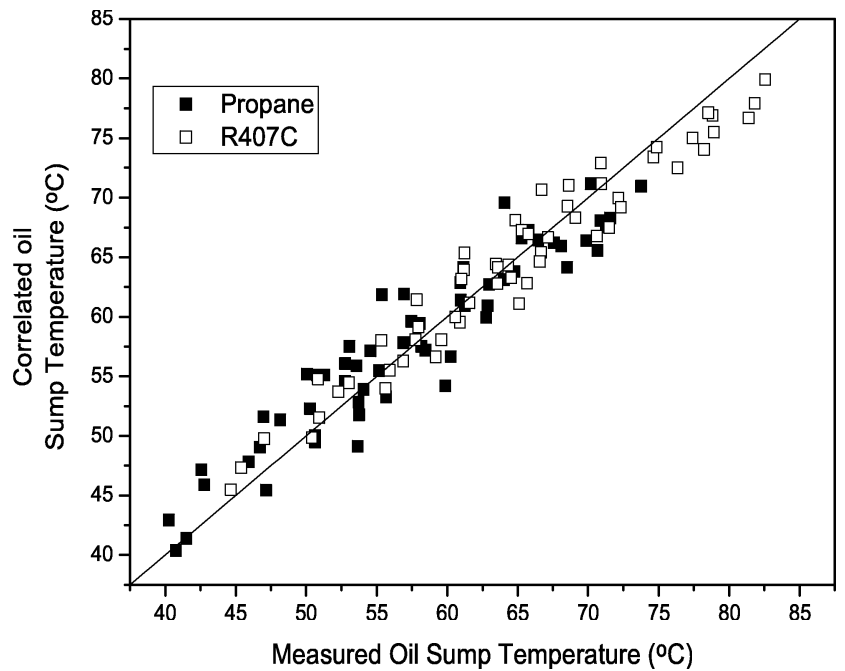

Figure 10. 


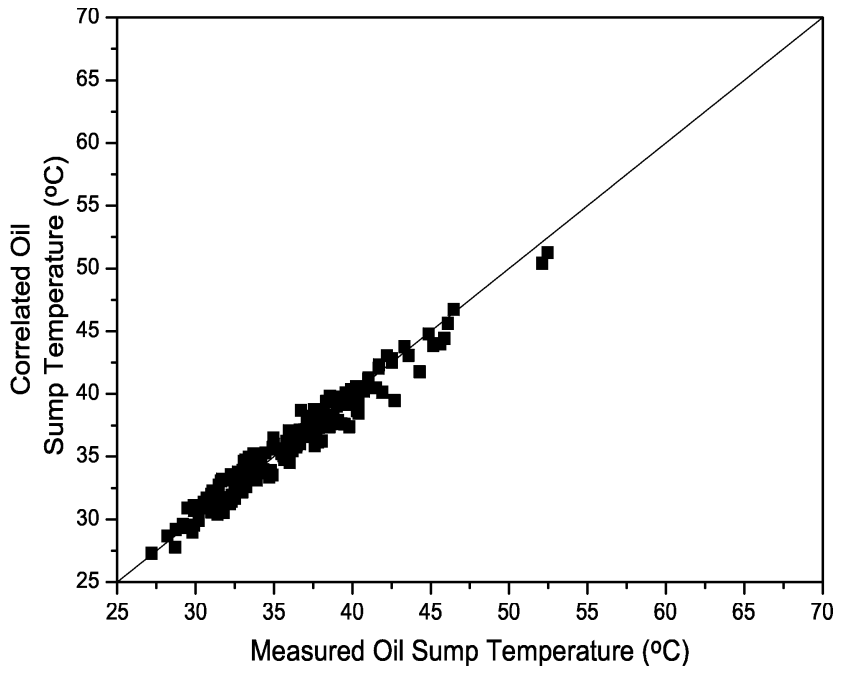

Figure 11. 

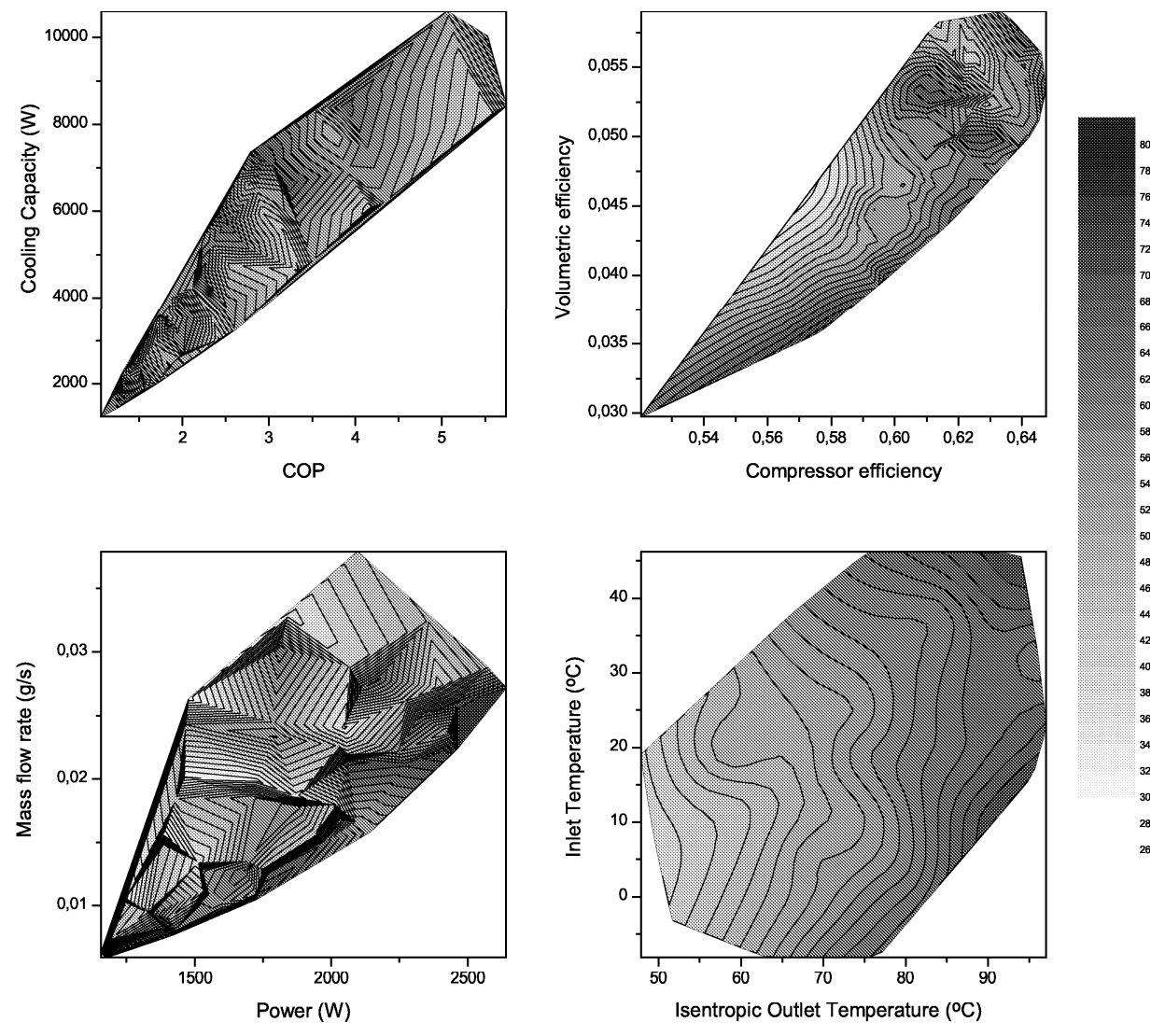


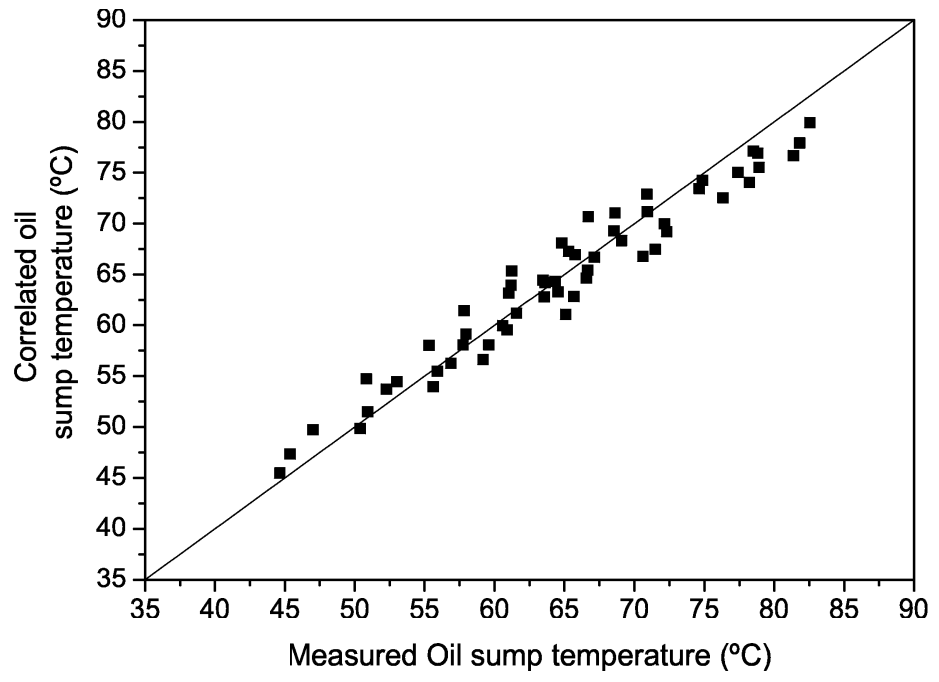

Figure 14. 


\begin{tabular}{|c|c|c|c|}
\hline Stroke (approx.) (mm) & Numb. of pistons & Dead Space ratio (approx.) & Compr. name \\
\hline 30 & 1 & 0.04 & one piston short stroke (SO) \\
\hline 40 & 1 & 0.03 & one piston long stroke (LO) \\
\hline 30 & 2 & 0.04 & two piston short stroke (ST) \\
\hline 40 & 2 & 0.03 & two piston long stroke (LT) \\
\hline
\end{tabular}

Table 1

Main characteristics of tested compressor 


\begin{tabular}{|c|c|}
\hline Compressor & Temperature $\left({ }^{\circ} \mathrm{C}\right)$ \\
\hline short stroke (SO) & $54.6 \pm 0.5$ \\
\hline long stroke (LO) & $62.3 \pm 0.7$ \\
\hline short stroke (ST) & $57 \pm 0.5$ \\
\hline long stroke (LT) & $63.9 \pm 0.5$ \\
\hline
\end{tabular}

Table 2

Mean compressor temperature for the reciprocating compressors working in the same conditions 


\begin{tabular}{|c|c|c|c|c|c|}
\hline Compressor & $C_{1}$ & $C_{2}$ & $C_{3}$ & Mult. corr. coeff. & Error \\
\hline one piston short stroke & $0.48 \pm 0.03$ & $0.10 \pm 0.04$ & $10 \pm 3$ & 0.97 & 1.8 \\
\hline one piston long stroke & $0.62 \pm 0.03$ & $0.10 \pm 0.03$ & $5 \pm 2$ & 0.99 & 1.2 \\
\hline two pistons short stroke & $0.459 \pm 0.016$ & $0.22 \pm 0.02$ & $13.3 \pm 1.4$ & 0.99 & 0.8 \\
\hline two pistons long stroke & $0.52 \pm 0.04$ & $0.20 \pm 0.03$ & $13 \pm 4$ & 0.97 & 1.2 \\
\hline scroll & $0.388 \pm 0.008$ & $0.36 \pm 0.04$ & $5.5 \pm 0.6$ & 0.97 & 1.0 \\
\hline
\end{tabular}

Table 3

Obtained coefficients for the linear regressions of oil temperature considering a dependence on discharge temperature and on evaporation temperature. 


\begin{tabular}{|c|c|c|c|c|c|}
\hline Compressor & $C_{1}$ & $C_{2}$ & $C_{3}$ & Mult. corr. coeff. & Error \\
\hline one piston short stroke & $0.54 \pm 0.07$ & $-0.13 \pm 0.08$ & $15 \pm 5$ & 0.90 & 3.5 \\
\hline one piston long stroke & $0,65 \pm 0,04$ & $-0,09 \pm 0,05$ & $14 \pm 3$ & 0.92 & 3.5 \\
\hline two pistons short stroke & $0.54 \pm 0.03$ & $-0.03 \pm 0.03$ & $18 \pm 2$ & 0.98 & 1.1 \\
\hline two pistons long stroke & $0.61 \pm 0.03$ & $-0.11 \pm 0.02$ & $22 \pm 2$ & 0.95 & 2 \\
\hline scroll & $0.50 \pm 0.04$ & $0.24 \pm 0.06$ & $4.5 \pm 0.8$ & 0.93 & 2 \\
\hline
\end{tabular}

Table 4

Obtained coefficients for the linear regressions of oil temperature considering a dependence on isentropic temperature and on evaporation temperature. 